\title{
Microcontroller based data acquisition system using error reduction technique
}

\author{
Don Biswas ${ }^{1 *}$, Kuldip Kumar ${ }^{2}$, Vishal Rohilla ${ }^{3}$, Gambheer Singh Kathait ${ }^{4}$, Prashant Thapliyal ${ }^{5}$, Arun \\ Shekhar Bahuguna ${ }^{6}$, Yogendra Pundir ${ }^{7}$, Vinay Prasad tamta ${ }^{8}$
}

\begin{abstract}
1,3,4,5 Department of University Science Instrumentation Centre, Hemwati Nandan Bahuguna Garhwal University, Srinagar Garhwal, INDIA
${ }^{2,6,7}$ Department of Electronic and Communication Engineering, Hemwati Nandan Bahuguna Garhwal University, Srinagar Garhwal, INDIA

${ }^{8}$ Department of Information Technology, Hemwati Nandan Bahuguna Garhwal University, Srinagar Garhwal, INDIA
\end{abstract}

\begin{abstract}
The application of high-speed real-time data acquisition is becoming increasingly wide spread in industrial field, and its measurement accuracy is also increasing. In the present study, the development of a USB based data acquisition system is presented here, where a microcontroller based standalone embedded system is used as data collection and also field control device. The data acquisition system has been calibrated in terms of output voltage generated in signal conditioner. The USB device system also calibrated for the error in the output result. Here USB device has been programmed as Human Interface Device (HID) class, hence not requiring any kind of device specific driver. This data acquisition system is utilized to measure the flow of a channel. The flow of water is not acidic.
\end{abstract}

Keywords: USB, microcontroller, PIC, acquisition, data acquisition, programmer, digital.

DOI: http://dx.doi.org/10.4314/ijest.v11i3.5

\section{Introduction}

From industrial view point, the physical parameter flow is a very critical constant for certain locations like, different types of power plant, field plant, DM plant, bottling plant, etc. Flow can be measure in two ways; one is dependent upon the volume and the other is dependent upon weight. Solid may be measured in terms of either weight per unit time or mass per unit time. The solid quantity is measured in terms of volume very rarely. The liquid quantity is characterized with the measurement of volume rate or in weight rate. The Gas quantity is normally measured in volume rate. The flow rate can be measured using different sensors like DPT type instrument, turbine flow meter. It basically measures the pressure difference between two points. The pressure difference is calibrated in terms of flow measurement. The data acquisition system has been also calibrated according to that purpose. The whole system has been calibrated using different techniques. First, we send some sinusoidal signal and analyze the correlation characteristic of the measured voltage peak data, which includes mean value, variance, standard deviation, range, deviation etc., and then finds out the influence rules of software timing error on data acquisition and measurement accuracy (Monoranjan and Sarma, 2010).

The sine-wave signal of this closed-loop test system is constructed by the SCIENTECH (ST4060) single-channel signal source, KEYSIGHT (Infinii Vision DSO-X 2024A) oscilloscope, and data acquisition card. In the high-speed data acquisition, the repeatability and reproducibility error can be reduced. The faster, reliable, efficient data acquisition system has been introduced in the field of modern measuring instrument (Pandey and Arora, 2019). With the rapid development of various measuring instruments and equipment, the demand for accuracy, loss reduction and real-time of data acquisition measurement is also increasing (USB-IF, 2006; Song et al, 2011; Zhao et al, 2012; Niculescu et al., 2019). The popularity of Universal Serial Bus (USB) has been extended due to its inexpensive and easy-to-use nature. The short range $(5 \mathrm{~m})$ communication medium has been used for the transfer of data from one device to another. In a regular PC (host), the communication device acts as a client (USB-IF, 
2006). The USB was originally designed to connect PC with its peripherals (keyboard, mouse etc.). However, it has proven useful for many other applications, including measurement and automation (Liptak, 1985; Chang and Liu, 2003; Shao et al, 2010; Liu and Qi, 2012; Zhang et al, 2014; Biswas et al, 2016; Biswas and Bahuguna, 2017). A work has been conducted on a flow measurement system, from which data has been acquired and measured.

\section{Methodology}

The measured signal has acquired by De-Sauty bridge and Output of this bridge is going to the unit called instrumentation amplifier. Instrumentation amplifier is basically a difference amplifier, which amplifies the signals from De-Sauty Bridge. Now the $1^{\text {st }}$ stage instrumentation amplifier output goes to the second stage amplifier which provides necessary amplification and zero, gain and span adjustment. Output of $2^{\text {nd }}$ amplifier which is an AC signal, is applied to the next unit, which is called rectifier and filter network (Figure 1) (Biswas et al, 2016).

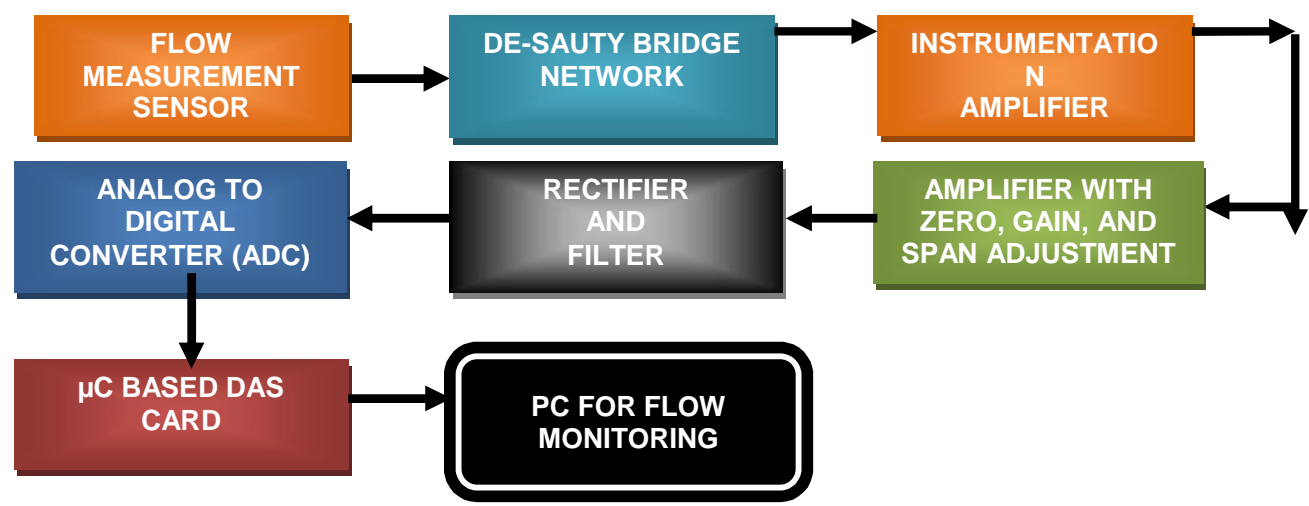

Figure 1: Water flow measurement system

The full wave rectifier output will pass through a filter network and ADC converter will convert the analog signal in the 8 bit digital signal. The USB based data acquisition system will acquire the data and collect it in the software which has been installed in the computer (Biswas and Bahuguna, 2017).

\section{Sensor part}

Flow may be of two types: viscous and turbulent. A restriction of known dimensions has been introduced in the case of variable head type flow meter sensor. This will increase a head loss or pressure drop at the restriction and will increase velocity in the flow. It may be used in a vertical line. The pressure drop across the obstruction will be the measurement or indication of the flow rate (Figure 2).

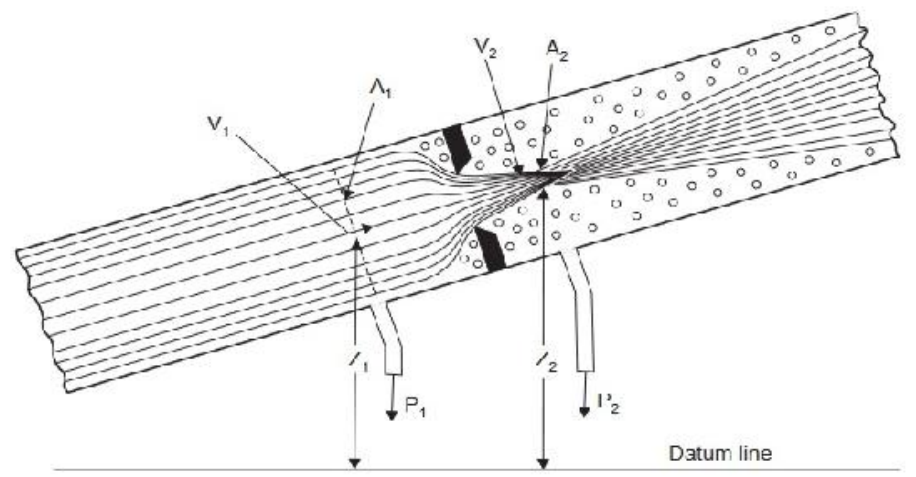

Figure 2: Detailed diagram of flow measuring system

The principle of the Head-type flow measurement is coming from the Bernoulli's theorem. The theorem states that in a flowing stream, the sum of the pressure head, the velocity head and the elevation head at one point is equal to their sum at another point in the direction of flow plus the loss due to friction between the two points. Velocity head is the pressure which is needed to increase the speed at which a liquid flows. Pressure head is the height of a liquid column that corresponds to a particular pressure exerted by the liquid column on the base of its container or pipeline (Liptak, 1985; Liptak, 2003; Liptak, 2006). 
The position of upstream and downstream tap are shown by Section-1 is and Section-2 respectively. Here, the terms are described as $\mathrm{T}=$ Temperature, $\mathrm{A}=$ Area, $\rho=$ Density, $\mathrm{V}=$ Stream velocity, $\mathrm{P}=$ Pressure and $\mathrm{Z}=\mathrm{Central}$ line elevation respectively. If this elevation is quite small such that $Z_{2}-Z_{1}$ is negligible, we may write the Bernoulli's equation for an incompressible $\left(\rho_{1}=\rho_{2}\right)$ frictionless and adaptive flow is written as

$$
\frac{P_{1}}{\rho}+\frac{V_{1}^{2}}{2 g}=\frac{P_{2}}{\rho}+\frac{V_{2}^{2}}{2 g}
$$

where, $g=$ acceleration due to gravity, giving

$$
P_{1}-P_{2}=\frac{V_{2}^{2} \rho}{2 g}\left(1-\left(V_{1} / V_{2}\right)^{2}\right)
$$

For Head- type of flow, the continuity equation is $Q=A_{2} V_{2}=A_{1} V_{1}$

where, $Q=$ volume flow rate in $\mathrm{m}^{3} / \mathrm{sec}$.

Combining Equations (1) and (2) and manipulating, one gets

$$
\begin{aligned}
& Q=A_{2} V_{2}=\frac{A_{2}}{\sqrt{\left(1-\left(A_{2} / A_{1}\right)^{2}\right.}}\left(\sqrt{\frac{2 g\left(P_{1}-P_{2}\right)}{\rho}}=A_{2} M_{v a} \sqrt{2 g h}\right. \\
& M_{v a}=\frac{1}{{\sqrt{1-\left(\frac{A_{2}}{A_{1}}\right)^{2}}}^{2}}=\text { Velocity approach factor }
\end{aligned}
$$

where $h=\left(P_{1}-P_{2}\right) / \rho=$ differential head

This is the equation for ideal volume flow rate (Liptak, 1985).

\section{Circuit Diagram}

The same DAS system has been utilized which is used and discussed in previous papers (Figure 3) (Biswas et al, 2016; Biswas and Bahuguna, 2017).

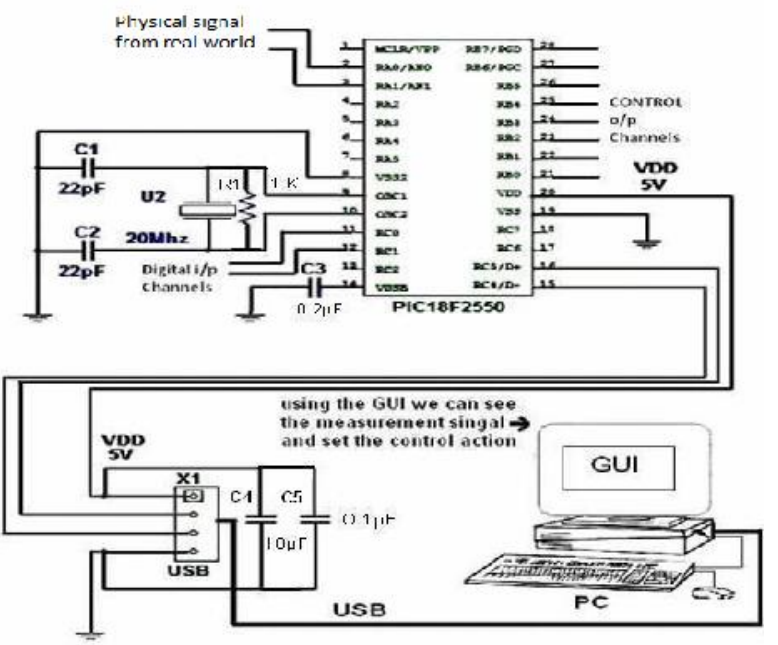

Figure 3: Circuit diagram of the measuring system 


\section{Results and Discussion}

The flow measurement first calibrated in terms of voltage signal and the USB based data acquisition system also checks for any error or data loss. In order to increase the efficiency and accuracy of the data acquisition system, the repeatability and reliability of the measurement and control process has been checked and the timing error of the system software was also analyzed and studied. Sine-wave signal was widely used in many fields, such as computer, communication and industrial control etc. (Zhang et al, 2014). The system is used sine wave signal of different frequencies using function generator SCIENTECH (ST4060) and the output amplitude see as test signal and KEYSIGHT (infiniiVision DSO-X 2024A) digital oscilloscope applied to monitor the test signal. SCIENTECH (ST4060) single-channel function/arbitrary waveform generator, not only produced accurate, stable and low distortion output signal, but also outputted the highest $1 \mathrm{MHz}$ sine-wave, meanwhile, it had seamless interconnect with KEYSIGHT series digital oscilloscope. At the same time, the system used DAS board to test signal through data acquisition system.

The DAS board was a multifunctional high-performance integrated interface board designed for industrial PC. The DAS board consists of a PIC 18F2550 series microcontroller (Manzanilla et al, 2009; Microchip, 2000). The board had 16-bit 16channel/differential 8-way A/D input, 4-channel 16-bit independent D/A output, and its inbuilt A/D converter chip adopted highperformance, the maximum conversion rate was up to $50 \mathrm{kHz}$ (Biswas and Bahuguna, 2017). The system adopted VB program to realize real-time programmable control of data acquisition card (Monoranjan and Sarma, 2009). Through the VB program timer control technique utilized to determine the sampling interval of data collection, the data acquisition of different test signals was carried out and the measuring precision of the collected datum were carried out. The overall test software frame and program interface were shown in Fig.4 and Fig.5. Figure 6 represents the flowchart of VB interface program to receive analog signal and digital signal (Michael, 2010; Li, 2017).

Setting SCIENTECH (ST4060) Single-channel function/arbitrary waveform generator to issue a working frequency of $50 \mathrm{~Hz}$, the peak-to-peak value of $1 \mathrm{~V}$ sine-signal, through the data acquisition card measured the peak-to-peak value of sine-wave signal, where the sampling timing was set to $100 \mathrm{~ms}, 150 \mathrm{~ms}, 200 \mathrm{~ms}$ respectively (Zhao et al, 2012). Three types of timer interval were set to minimum value, carried out comparative test to data measurement accuracy, and each group of tests repeated five times, the results were as shown in Table 1.

Table 1: Peak voltage data acquisition at different sampling time (V)

\begin{tabular}{|c|c|c|c|}
\hline Sampling Time & $100 \mathrm{~ms}$ & $150 \mathrm{~ms}$ & $200 \mathrm{~ms}$ \\
\hline Visual Basic & $0.9523 \mathrm{v}$ & $0.8752 \mathrm{v}$ & $0.7894 \mathrm{v}$ \\
\cline { 2 - 4 } Timing & $0.9876 \mathrm{v}$ & $0.7853 \mathrm{v}$ & $0.7845 \mathrm{v}$ \\
\cline { 2 - 4 } Technique & $0.95236 \mathrm{v}$ & $0.7845 \mathrm{v}$ & $0.8452 \mathrm{v}$ \\
\cline { 2 - 4 } & $0.89023 \mathrm{v}$ & $0.6578 \mathrm{v}$ & $0.7564 \mathrm{v}$ \\
\hline
\end{tabular}

The system is more advantageous than the traditional serial communication system. The received data loss is very minimum and the system is more reliable and efficient. With the advancement of the USB system, the connecting output devices will work faster and efficiently (Pandey and Arora, 2019). Figures 7- 12, are shown for the purpose of calibration of that data acquisition system.

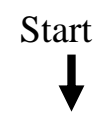

Set data acquisition time

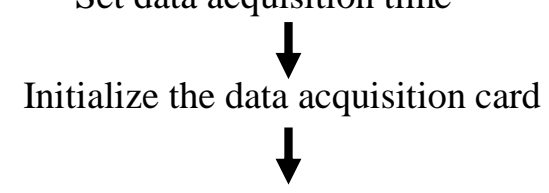

The VB timer control timing

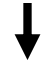

Data acquisition and processing

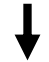

Close the data acquisition

End

Figure 4: Program flow of data acquisition system 


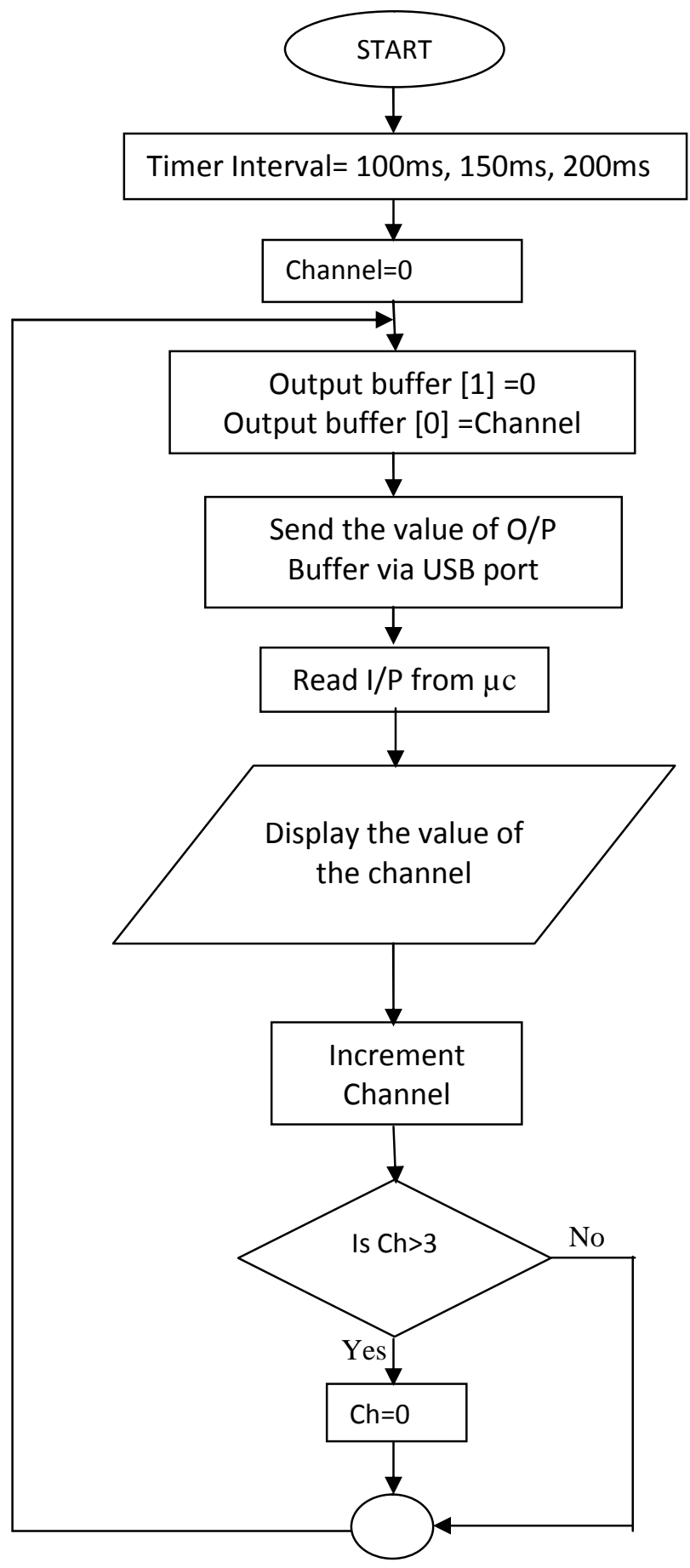

Figure 5: The Flowchart of VB program to receive analog and digital signal values 


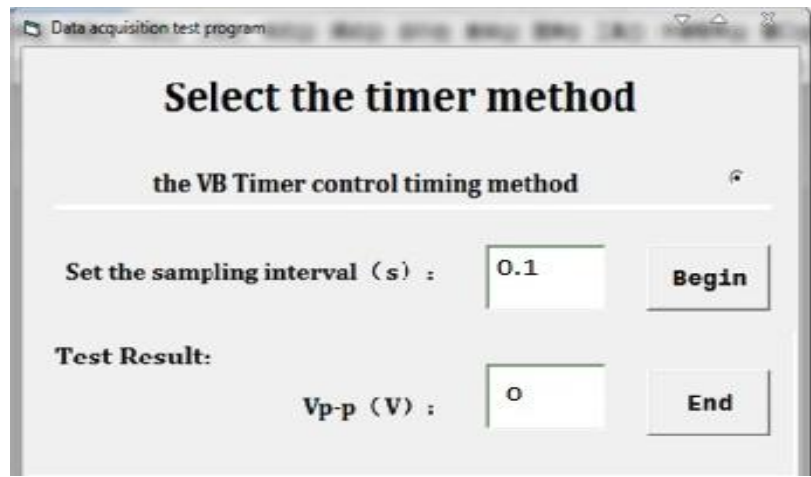

Figure 6: Test program interface

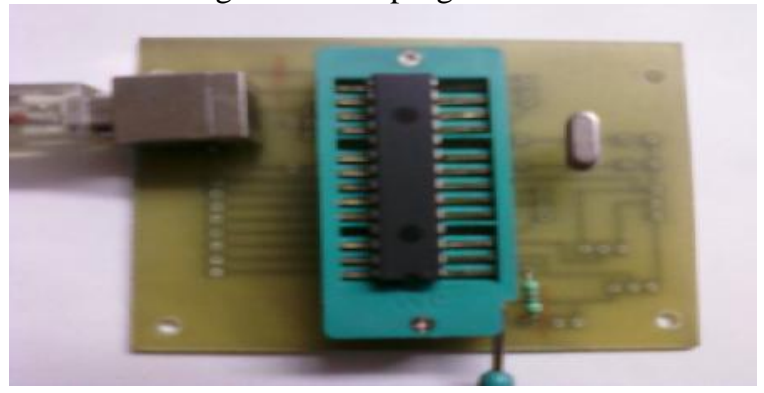

Figure 8: Microcontroller connected with USB

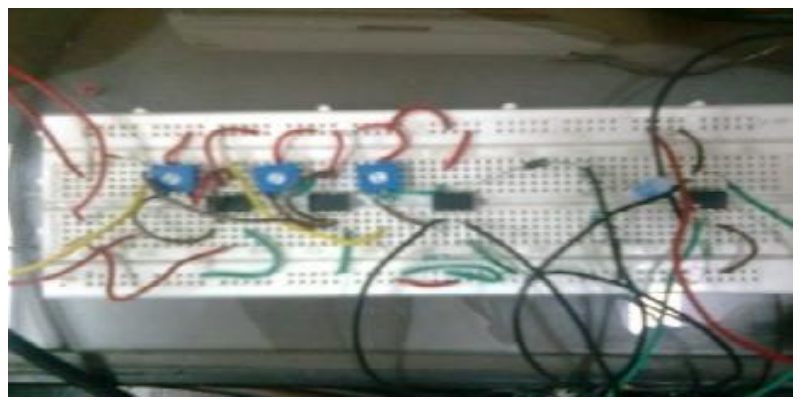

Figure 10. Circuit board

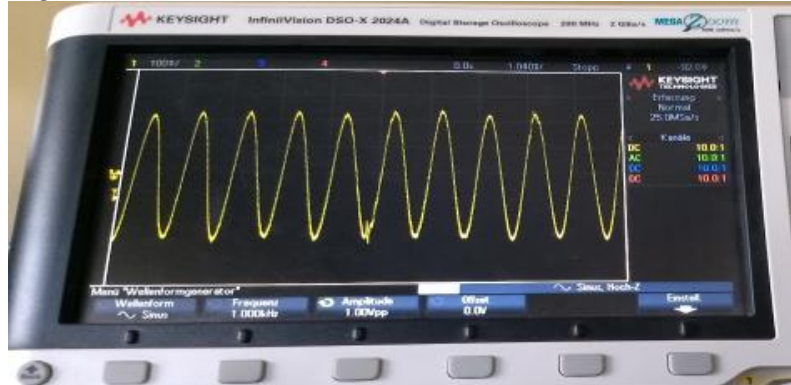

Figure 12: Microcontroller connected with USB and sinusoidal wave generated for calibration purpose

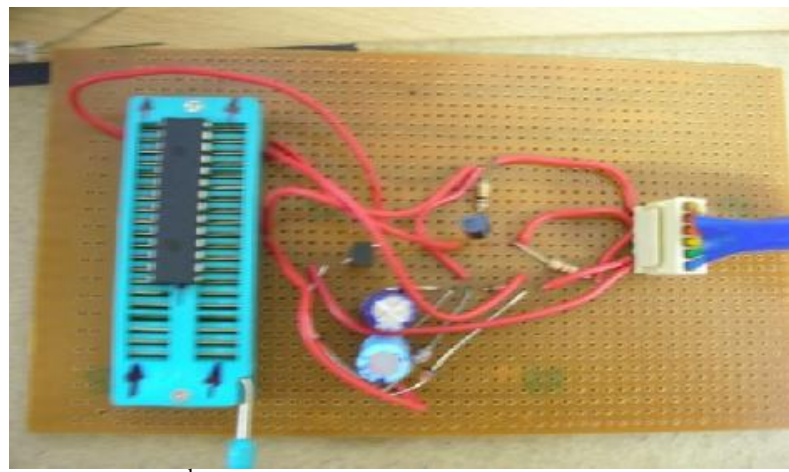

Figure 7: $2^{\text {nd }}$ Generation JDM programmer

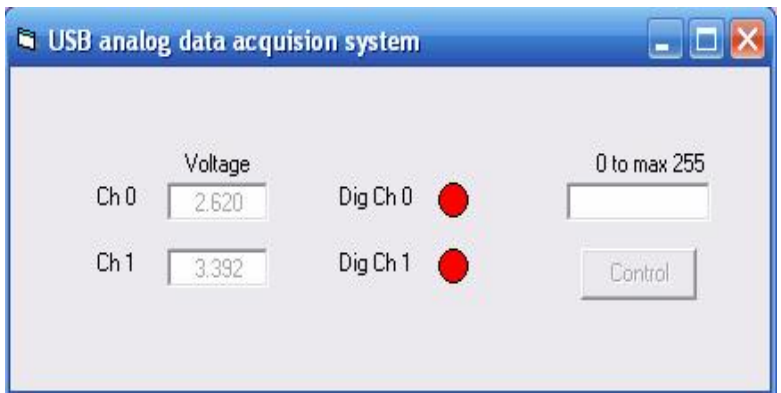

Figure 9: Analog data is being displayed and both digital channels are at logic ' 0 '

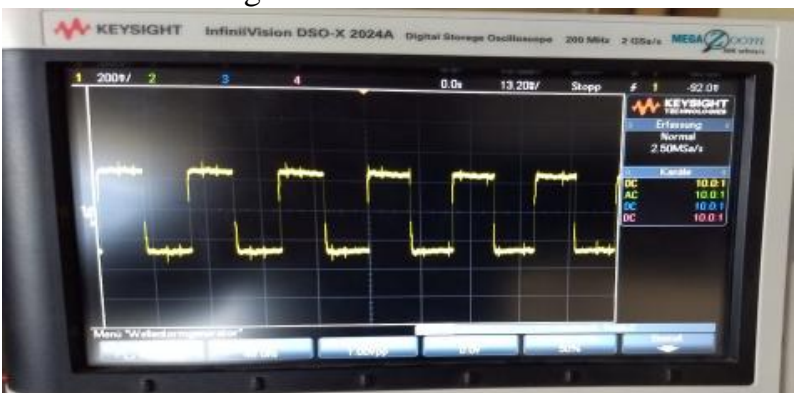

Figure 11: Square wave generated in CRO

Repeatability error refers to the random error obtained from the same direction for multiple continuous measurement of the same input value in the whole measurement range and under the same working condition. The error has been measured and calculated. The mean value and Standard Deviation also calculated. The electronic flow measuring meters are used in many applications where the flow rate is vertical, and stream rate must be continuously monitored and checked. The data collected in a computer using a USB based data acquisition system (Ziad et al., 2006). The flow measuring meters have a limited range of operation. For turbine flow meters, the output DC voltage signal from the signal conditioner has been calibrated such that it will be proportional to the flow rate of the main stream. We calibrated the flow rate using this technology in a certain linear range to measure flow rate and draw a graph of flow verses voltage. The block diagram (Figure 13) demonstrates the whole process and the precision turbine flow meter shown in Figure 14 (Omega, 2000) is placed within that loop; the tank has a height (Omega, 2000). So, there is a 
constant head pressure because of the water tank and the loop has 1/2-inch copper piping, 3/8-inch plastic flexible tubing, 3/8-inch brass flow straightening sections (18-diameters long) upstream and downstream of the flow meter, a 90- $\mu \mathrm{m}$ filter (Swagelok, Model SS-6TF-90) upstream of the flow straightening section and a ball valve upstream of the filter for adjusting the flow rate (Swagelok, 2000).

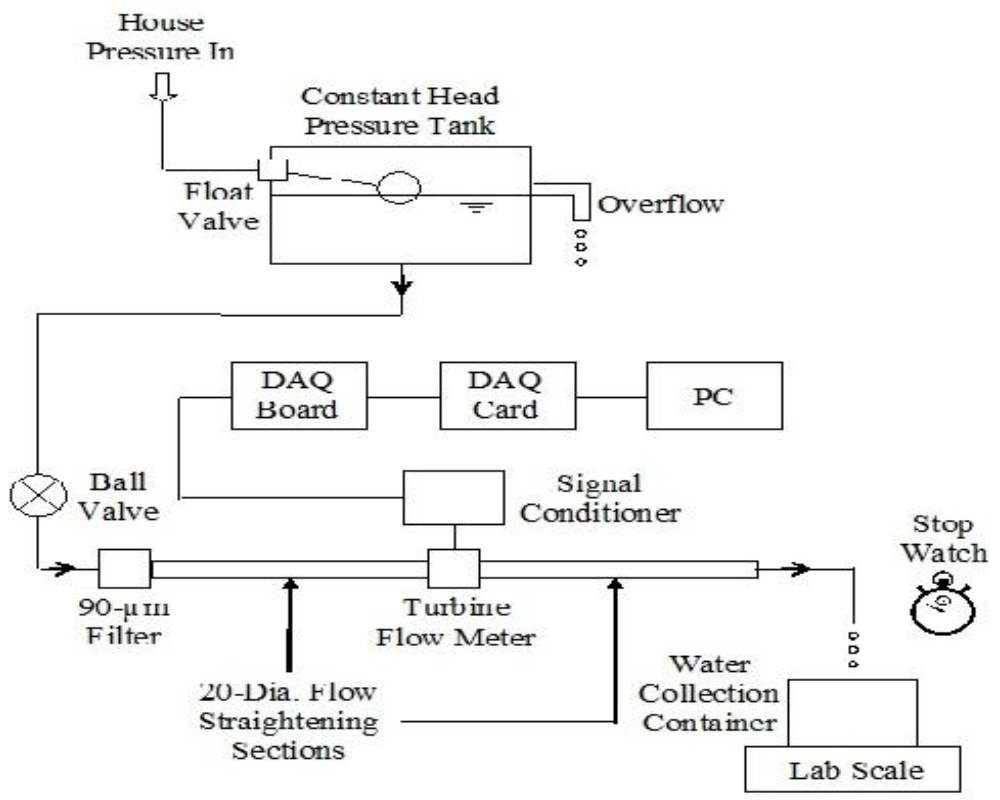

Figure 13: block diagram

The flow meter is attached to a signal conditioner (Model No. FLSC-61) and electrical voltage (12V DC) is connected to the signal conditioner with a power supply [FLSC-6, 2003]. A data acquisition card is set to acquire input data from the signal conditioner by opening the Visual Basic software on the personal computer [Michael, 2010]. The PC and DAS card already calibrated for measurement purpose and measure the flow of water by using the flow meter/signal conditioner voltage at the maximum mass flow rate achievable by the flow loop system, and the voltage at the minimum mass flow rate readable by the flow meter. We divide the range into ten equally-spaced nominal mass flow rate settings for the purpose of obtaining a mass flow rate calibration equation. We set the mass flow rate to one of the nominal values discussed above using the ball valve. The DAS card is installed in order to collect voltage data from the flow meter/signal conditioner [Ziad et al, 2006]. We measured the mass flow rate by hand five consecutive times while the DAS collects voltage data at a rate of one reading every 0.2 seconds as follows:

(i) A water collection container has been set on the measured scale $(\mathrm{cm})$ and set zero scale level.

(ii) Placed the container under the stream of water exiting the flow meter and simultaneously start a digital stop watch.

(iii) Collected the water from the source for approximately 60 seconds.

(iv) After that withdraw the container from the water stream, and simultaneously stop the timer.

Measure the mass of liquid in the collection container using the measured scale and recorded it by hand.

According to the mass flow readings the calibration equation (may be the form of linear equation) for the flow meter will be found by plotting the mass flow rate readings versus the corresponding mean voltage readings, as shown below in Figure 15. The flow rate is linear (although not exactly) with respect to the voltage reading.

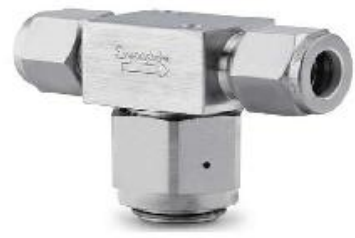

Figure 14: Turbine flow meter (FTB-9506) 


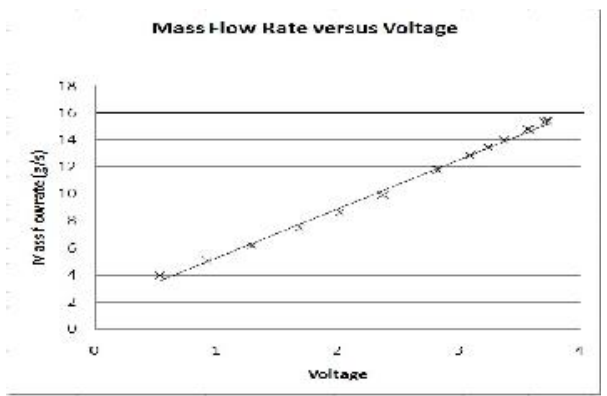

Figure 15: Variation of Mass flow rate with voltage

\section{Conclusion}

It has been observed that high speed data acquisition system have data loss also. Though using the error reduction technique we can optimize the error and collect the data accordingly. The advantage of this system is to reduce data loss error, while measuring any kind of physical parameter. The measured data, which is going through the USB acquisition system, so that, the serial communication is faster. The previous DAQ system is slow and too much data loss is taking place. The DAQ device may not be put at too much distance. They are not reliable according to the previously published papers. Taking the sine-wave as the test signal, from the sampling time length, the signal waveform analysis and the frequency three aspects, carries on the analysis to the measured voltage peak data correlation characteristic, including the mean value, variance, standard deviation, range, variation coefficient, deviation, kurtosis and so on.

\section{References}

Biswas D., Kathait G. S. and Rohilla V., 2016. To Design and Measure Physical Signal from a USB Based Data Acquisition System. International Journal of Latest Technology in Engineering, Management \& Applied Science, Vol. 5, No.8, pp. 75-81.

Biswas D., and Bahuguna A., 2017. To Measure Physical Signal from Sensor and Control through Data Acquisition System. International Journal of Advanced Research in Computer Science and Software Engineering, Vol. 7, No. 5, pp. 377-388.

Chang F L, and Liu J., 2003. The application of multimedia timer in the fast data acquisition under the multi thread. Computer application, Vol. 23, No. 6, pp. 177- 178.

FLSC-6, 2003. Signal Conditioner, USA, Accessed 1 October 2018 〈http://www.omega.com/manuals/manualpdf/M2729.pdf〉

Liu H, and Qi Q. X., 2012. Design of a sine- wave measuring device based on STM32. Modern Electronics Technique, Vol. 17, No. 35, pp. 110-115.

Liptak G. B., 1985. Process Instruments and Control Handbook, $3^{\text {rd }}$ Edition, McGraw Hill, New York, USA, pp. 1-1766.

Liptak G. B., 2003. Instrument Engineers' Handbook, $4^{\text {th }}$ Edition, Taylor \& Francis, London, New York, USA, pp. 1-46.

Li Y L., 2007. Basic Visual programming. China, Beijing, Tsinghua University press, $2^{\text {nd }}$ Edition, pp. 96-320.

Liptak G. B., 2006. Instrument Engineers' Handbook, $4^{\text {th }}$ Edition, Taylor \& Francis, London, New York, USA, Vol. I \& II, pp. 1$60 \& 1-67$.

Manzanilla G., Silva A., Barrera M., 2009. Temperature-Meter via USB Based on PIC 18F2550 for Solar Energy Concentrator System. 19th International Conference on Electrical, Communications, and Computers, Cholula, Puebla, Mexico, pp. 1-7.

Michael H., 2010. Microsoft Visual Basic 2010 Step by Step Theory and Applications, Microsoft Visual Basic 2010 Step by Step, $1^{\text {st }}$ Edition, Redmond, Washington, Microsoft Press store by Pearson, pp. 1-576. [Online]

https://www.microsoftpressstore.com/store/microsoft-visual-basic-2010-step-by-step-9780735645387

Microchip, 2000. Microcontroller chip PIC 18F2550 datasheet, Arizona, Accessed 1 October 2018 〈http://www.microchip.com>

Monoranjan N. S. and Sarma K. C., 2009. Low cost PC based real time data logging system using PCs parallel port for slowly varying signals. The journal of Assam Science Society, Vol. 50, No. (1-2), pp. 36-41.

Monoranjan N. S. and Sarma. K. C., 2010. Design of PIC 12F675 microcontroller based data acquisition system for slowly varying signals. The journal of Instrument Society of India, Vol. 40, No. 1, pp 15-17.

Niculescu, Titu; Popescu, Florin Gabriel; Marcu, Marius; Slusariuc, Ioan Răzvan, 2019. Improving the quality of measurements in electrical processes using NI USB data acquisition systems. Calitatea, suppl. Quality-Access to Success: Acces la Success, Bucharest, Vol. 20, Iss. S1, pp. 293.

Omega, 2000. FTB-9506, Turbine Flow Meter, USA, Accessed 1 October 2018 $\langle$ http://www.omega.com/manuals/manualpdf/M2728.pdf>

Pandey A.K., Arora S., 2019. Onboard Data Acquisition System to Monitor the Vehicle. Advances in Intelligent Systems and Computing, Springer, Singapore, Vol. 904. pp. 265-271.

Song P. F., Wang H. J., Zeng H., 2011. Research and design of high speed and deep storage data acquisition System. Journal of instrumentation, Vol. 4, No. 32, pp. 903-912. 
Swagelok, 2000. Model SS-6TF-90 Filter, USA, Accessed 1 October 2018 <https://www.swagelok.com/en/catalog/Product/Detail?part=SS-6TF-90>

Shao Y. Y., Xu. X. D., Xuan G. T., 2010. Application of multimedia timer in real time data acquisition of machinery. Computer and Information Technology, Vol. 18, No. 2, pp. 16-18.

USB-IF, 2006. Universal Serial Bus, USA, Accessed 1 October 2018 〈http://www.usb.org/about>

Zhao D. J., Jia J., Gao X. G., He X. L. and Li J P., 2012. High field asymmetric waveform ion mobility spectrum of sinusoidal waveform generation and ion separation characteristics. Journal of Sensing Technology, Vol. 7, No. 25 , pp. $926-929$.

Zhang H., Wang J. M., Cui K, et al., "A data transmission and time measurement system for bit commitment experiment. $19^{\text {th }}$ IEEE-NPSS. IEEE (Real Time Conference), Nara, Japan, pp. 1-2.

Ziad S., Alaa Al B. and Ismail Al K., 2006. A Novel Design of an Industrial Data Acquisition System. $2^{\text {nd }}$ International Conference on Information \& Communication Technologies, Damascus, Syria, pp. 2589 - 2594.

\section{Biographical notes}

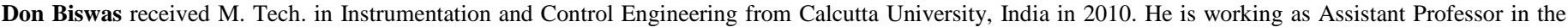
Department of Instrumentation Engineering, HNB Garhwal University. His research interests include Material engineering, Data acquisition System, etc.

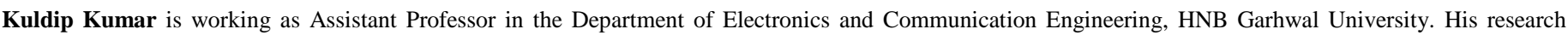
interests include Communication Engineering.

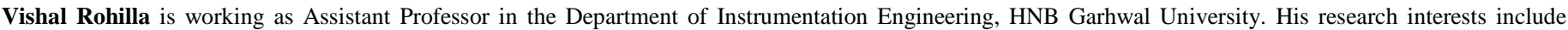
Material engineering, Instrumentation, Analytical Instruments, etc.

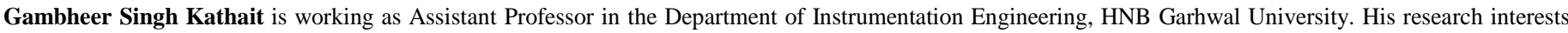
include Material engineering, etc.

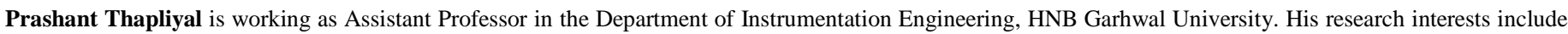
Material Science, etc.

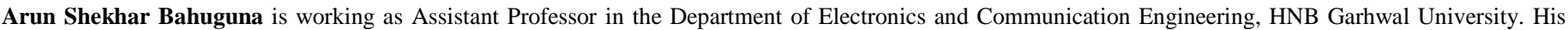
research interests include Communications, Antenna Systems, etc.

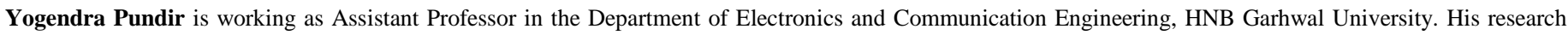
interests include Communication Systems, etc.

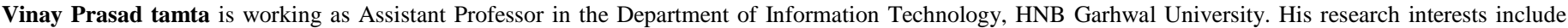
Information Technology, etc.

Received November 2018

Accepted May 2019

Final acceptance in revised form May 2019 